\title{
WHAT FACTORS INFLUENCE PROFITABILITY IN THE KOREAN CREDIT CARD BUSINESS?
}

\author{
Ji-Yong Seo \\ Sangmyung University
}

\begin{abstract}
This study investigates the hypothetically influential factors in the profitability of Korean credit card firms based on the findings of previous studies. By using recent Korean credit card business data, the study determines whether internal and external factors affect profitability in the operating activities of credit card firms. The main findings are as follows. First, Korean credit card firms are mainly affected by the portion of the interest margin contribution from the perspective of business diversification. Second, the level of risk management in Korean credit card firms plays a critical role in enhancing their profitability. Third, large asset investment is not helpful in increasing the profitability of Korean credit card firms.
\end{abstract}

Keywords: Hypothetically Influential Factors; Interest Margin Contribution; Level of Risk Management; Large Asset Investment.

\section{INTRODUCTION}

Until recently, the policy for disputes over reducing the fee rate for self-employed small business credit card affiliates had been progressed in Korea. Small business owners argued that $1.5 \sim 2.0 \%$ of the current credit card affiliate fee, which is to be paid to credit card firms in order to receive the proceeds of sales in advance, is too high for them to manage their businesses. In addition, small-sized credit card affiliate owners have held that credit card firms could make an operation profit regardless of the change in the card affiliate fee because they benefit from the huge interest margin from the card loan and cash advance services.

On the contrary, credit card firms have argued that the reduction in the affiliate fee places a serious burden on the credit card industry because the diversification of the Korean credit card business is not well performed.

However, the Korean financial authority recently announced a $0.7 \%$ cut in the fee rate for small business owners. To protect small credit card affiliates with sales amounts less than USD 270,000 per year, some members of the opposition party in the Korean Congress strongly argued that the government should reduce the fee to a low percentage but only for small business owners despite the opposition of credit card firms since early 2015.

- Corresponding author: Department of Business Administration, Associate Professor, Sangmyung University, Seoul, Korea. Phone: +82 22287 5487, E-mail: jyseo@smu.ac.kr 
In light of this controversial issue of the profitability of Korean credit card firms, this study aims to determine the pivotal factors in the profitability of credit card firms. Amid the changing business environment in the Korean credit card industry, this study could contribute to an innovative policy solution by analyzing the factors that influence profitability.

The paper is organized in the following manner. Chapter 2 discusses the theoretical background of the profitability of financial institutions such as credit card firms by reviewing previous studies. Chapter 3 outlines the data and empirical test model, Chapter 4 analyzes the results, and the final chapter concludes the study.

\section{THEORETICAL BACKGROUND}

The determinants of profitability of financial institutions are a popular topic in financial research because this factor is essential for the sustainable management of modern financial institutions. Seo (2014) regarded the profitability of Korean credit card firms as an essential factor in financial stability, in addition to capital adequacy and loan soundness. However, there are few previous studies on the profitability of financial institutions other than banks. By referring to previous studies, this paper examines the hypothetically influential factors in the profitability of financial institutions.

Recent studies (Akin, Aysan, Kara, and Yildiran, 2011; Islam and Ahmed, 2012; Tan and Floros, 2014) suggested that market competitiveness, which an external factor reflecting the characteristics of an industry, is a critically influential factor in the profitability of financial institutions. In their examination of the Turkish credit card industry, Akin, Aysan, Kara, and Yildiran (2011) pointed out that the card rate is the proxy index for market competitiveness. Islam and Ahmed (2012) also argued that the level of competitiveness in the credit card industry in Bangladesh plays a pivotal role in determining the profit size. In addition, after examining Chinese financial institutions, Tan and Floros (2014) concluded that the profitability of a financial institution is negatively affected by the fierce competitiveness among rival companies. In addition, Demirguc-Kunt, Laeven and Lebine (2003) demonstrated a correlation between intensifying market competition and a small margin between lending and borrowing rates.

Previous studies have considered external factors such as macroeconomic and financial market variables. Pasiouras and Kosmidou (2007) argued that compared to manufacturing firms, financial intermediaries' profitability is influenced by financial markets and macroeconomic conditions. Shin (2012) showed that the profitability of financial institutions is negatively affected by unexpected financial market turmoil and macroeconomic instability such as the global financial crisis of 2008. Shin argued that the profitability of Korean financial institutions is susceptible to external economic and financial market conditions. In particular, Blejer, Feldman and Feltenstein (2002) insisted that changes in a financial market, such as high policy rates, could erode business profitability by increasing the number of bad debts and loan-loss provisions. Kassim and Manap (2008) analyzed the effects of interest rate shock on household loans in Malaysia and found that card loans and auto loans were especially sensitive. In a recent study, Bellotti and Crook (2013) proposed a dynamic model for predicting default by credit card users by using simulated economic conditions. Hyun (2014) argued that the profitability of the credit card business is mainly created by the net interest margin. 
Kassim and Manap (2008), Shin (2012), Bellotti and Crook (2013), and Hyun (2014) showed that changes in the external factors of the macroeconomy and the financial market play a significant role in determining the profitability of credit card firms.

However, some previous studies considered internal factors, such as financing capability, business portfolio, risk management level, and firm size. Demirguc-Kunt and Huizinga (2010) asserted that the profitability of financial intermediaries depends on their funding structure. In their study of financial institutions in 75 countries, Quayes and Hasan (2014) tested the relationship between operating profit and financial disclosure, finding that voluntary financial disclosure could contribute to improving profitability. Based on the argument by DemirgucKunt and Huizinga (2010), the evidence from the study of Quayes and Hasan (2014) implies that a good reputation of the stakeholders in the market enhance the financing capability of financial institutions. Thus, it is plausible that the internal factor of financing capacity may contribute to increasing the profitability of financial institutions.

Shin (2012) suggested that in terms of financial institution management, internal factors, such as a well-diversified portfolio in business composition, are necessary in creating profit. In particular, Stever (2007) argued that smaller firms diversify their business to a lesser extent, which exposes them to greater risks. Regarding firm size, Lee, Lin, and Chen (2010) suggested that the larger a firm is, the greater the amount of profit it creates. On the contrary, Carter and McNulty (2005) demonstrated a negative correlation between asset size and business profitability.

Regarding another internal factor in the profitability of financial institutions, Xiong, Wang, Mayers, and Monga (2013) and Sohn, Lim, and Ju (2014) examined the probability of the default rate of borrowers by using personal information and the credit lines of credit card users. The findings imply that credit card firms can predict the default rates of borrowers by analyzing specific information about credit card customers. The reason is that compared with other financial institutions, credit card firms have access to detailed customer information. Thus, it is plausible that the level of risk management in credit card firms is an internal factor that may affect their profitability.

\section{DATA AND METHODOLOGY}

\subsection{Data}

Based on the hypothetical variables affecting the profitability of credit card firms found in previous studies, this study used macroeconomic and financial market variables with the characteristics of credit card firms. The main sources of the raw data are the Financial Statistics Information System of the Financial Supervisory Services and the Economic Statistics System of The Bank of Korea. The period of analysis is from quarter 1 of 2000 to quarter 2 of 2015. To reflect the recent economic conditions of financial markets and credit card firms in Korea, the latest data provided by the Financial Supervisory Services and Economic Statistics System were compared with Seo (2014) and Hyun (2014), which used Korean data. 


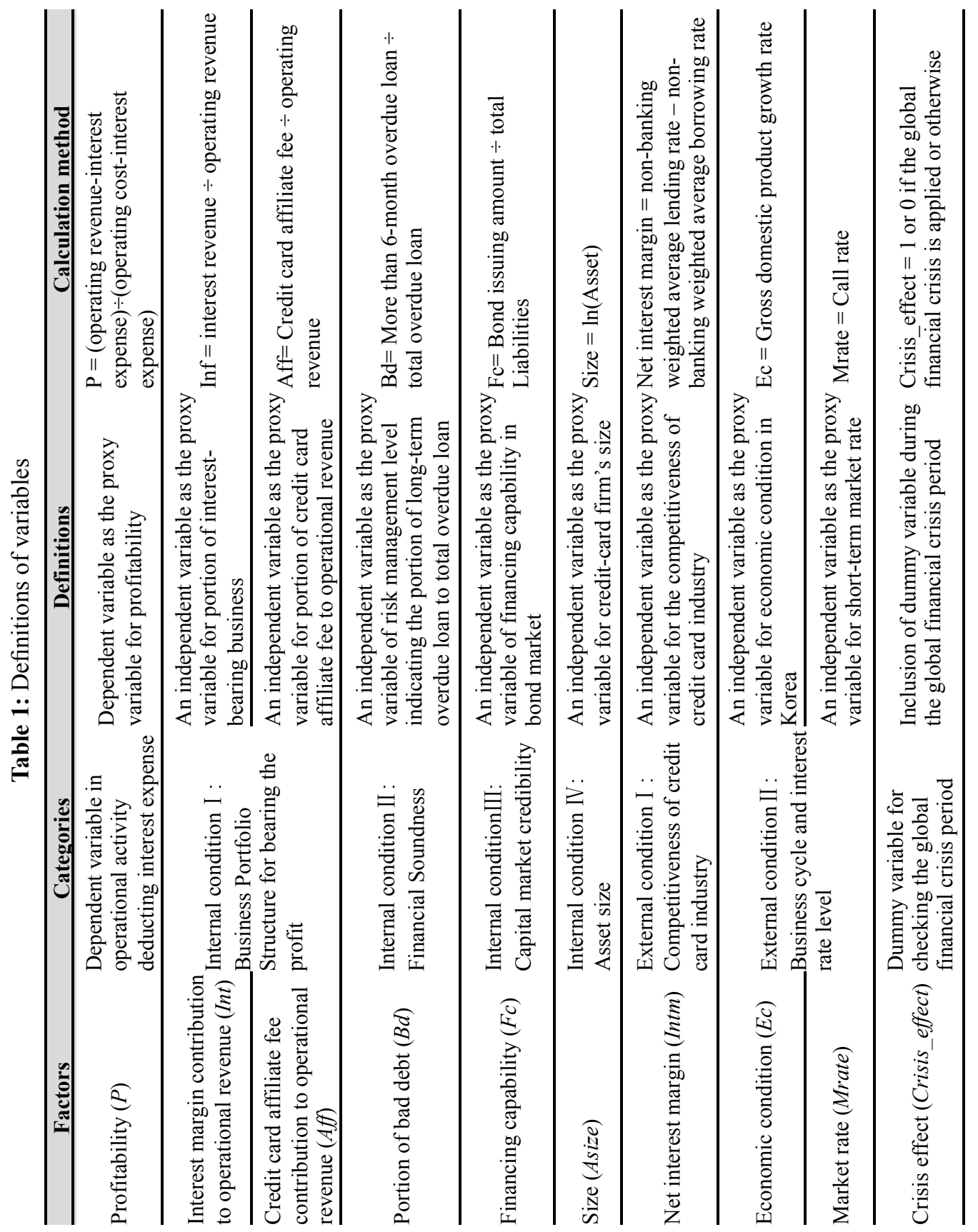


Table 1 shows the main proxy variables as dependent and independent variables. According to Table 1, the dependent variable of the proxy variable for profitability is the ratio of operating revenue to operating cost with the deduction of the interest expense. Based on Quayes and Hasan (2014) and Seo (2014), the current study adopts the performance of operating activity as the proxy variable of profitability.

The independent variables are categorized as internal factors and external factors based on the credit card firms. The contributions of the interest margin ( Int ) and the credit card affiliate fee $(A f f)$ to operational revenue are considered internal factors. These variables were adopted from Hyun (2014), in which the net interest margin is the main source of the profitability of the Korean credit card industry. It is also a recent, controversial issue in Korea regarding the reduction of the credit card affiliate fee. In addition, the internal factors of portion of bad debt $(B d)$, financing capability ( $F C$ ), and size (Asize) are included in the testing model based on the findings of Xiong, Wang, Mayers, and Monga (2013), Demirguc-Kunt and Huizinga (2010), and Lee, Lin, and Chen (2010).

However, the present study also takes into account external factors, such as economic growth rate and market rate, which were examined in Blejer, Feldman and Feltenstein (2002), Kassim and Manap (2008), Shin (2012), Bellotti and Crook (2013), Seo (2014), and Hyun (2014). In particular, the present study uses the dummy variable of the financial crisis to distinguish from normal periods, which is departure from the methodology used in previous studies such as Seo (2014).

\subsection{Model}

The equation shown at the end of this paragraph is used to test the variables empirically, which consist of profitability ( $P$ ), 8-independent variables, and the dummy variable of the crisis effect. However, this study considers the time lag as far as the internal factors, that is, the independent variables, are concerned in order to prevent the simultaneity problem. The reason is that the dependent variables are the financial ratios derived from the financial information of credit card firms. To confirm the robustness of the estimated coefficients through the various model specifications, four types of model specifications are tested, depending on the categories of independent variables included in the equation: internal factors, internal factors with the external factor of the competitive industry, internal factors with all external factors, and internal and external factors with the crisis effect.

$$
P_{t}=\beta_{0}+\beta_{1} \text { Int }_{t-1}+\beta_{2} A f f_{t-1}+\beta_{3} B d_{\mathrm{t}-1}+\beta_{4} F c_{t-1}+\beta_{5} \text { Asize }_{t-1}+\beta_{6} \text { Intm }_{t}+\beta_{7} E c_{t}+\beta_{8} \text { Mrate }_{t}+\left(\text { Cirsis_effect }_{t}\right)+e_{t}
$$

\section{RESULTS}

\subsection{Basic statistics}

Table 2 shows the results of the variables tested. No variable showed a normality distribution except the proxy variables of financing capability $(F c)$ and market rate (Mrate). The reason is that the Jarque-Bera test showed statistical significance. Among the variables, the external variables, such as net interest margin ( Intm ), economic condition ( $E c$ ), and market rate ( Mrate), showed high volatility compared with the internal factors. 
Table 2: Basic statistics

\begin{tabular}{ccccccc}
\hline Variables & Jarque-Bera & Mean & Median & Standard deviation & Minimum & Maximum \\
\hline$P$ & $51.24 * * *$ & 1.1311 & 1.1712 & 0.5743 & -0.6888 & 3.4381 \\
Int & $54.40^{* * *}$ & 0.0340 & 0.0234 & 0.0279 & 0.0053 & 0.1217 \\
Aff & $7.35^{* *}$ & 0.3527 & 0.4476 & 0.1561 & 0.0869 & 0.5893 \\
$B d$ & $40.27 * * *$ & 0.0068 & 0.0046 & 0.0058 & 0.0017 & 0.0027 \\
$F c$ & 3.38 & 0.5798 & 0.5986 & 0.1460 & 0.2824 & 0.8215 \\
Asize & $5.45 *$ & 17.7229 & 17.6260 & 0.4097 & 17.0985 & 18.3406 \\
Intm & $33.20^{* * *}$ & 6.3769 & 6.3700 & 1.3537 & 0.90000 & 9.9300 \\
Ec & $414.89 * * *$ & 0.9197 & 0.90000 & 1.1324 & -5.1000 & 3.8000 \\
Mrate & 3.55 & 3.5152 & 3.5500 & 1.0625 & 1.6800 & 5.3500 \\
\hline
\end{tabular}

Notes: $*$, ${ }^{*}$, and $* * *$ denotes significant at $10 \%, 5 \%$, and $1 \%$ level, respectively.

\subsection{Empirical results}

Table 3 shows the statistically significant coefficients of the profitability to independent variables categorized by internal and external factors. The table shows in in consecutive order the four model specifications designed to determine the influence of hypothetical factors on profitability. Model specification 1 includes the hypothetical internal factors in the profitability of credit card firms. In the case of the model specification, net interest margin, which represents market competitiveness as an industry characteristic, is included. Model specification 3 includes all external factors, and model specification 4 includes the crisis effect.

The results showed that all internal factors were significant in the specifications for model 1 and model, which included the internal factors. Thus, the contribution of interest margin to revenue ( Int ), credit card affiliate fee contribution to revenue ( Aff ), portion of bad debt $(B d)$, financing capability $(F c)$, and firm size (Asize) were factors that influence profitability. However, the contribution of interest margin to revenue ( Int ), portion of bad debt ( $B d$ ), and financing capability $(F C)$ were statistically significant regardless of the model specifications. In addition, their estimated coefficients' signs showed consistency.

As expected, the results showed that contribution of interest margin was a pivotal factor in the profitability of Korean credit card firms, which confirms Hyun (2014). However, the contribution of the credit card affiliate fee to revenue, which is a current issue in Korea, was not significantly correlated to the profitability of Korean credit card firms. The estimated coefficients, -0.0012 and -0.0012 , in model 3 and model 4 specifications, respectively, which included all hypothetical factors, were not significant even though they showed significant coefficients if only internal factors were considered.

At the level of risk management, portion of bad debt was strongly negatively significant regardless of the model specifications. The coefficients of portion of bad debt were -0.1071 , $-0.1072,-0.1030$, and -0.1042 . This result implies that the higher the risk management level, the greater the increase in the profits of Korean credit card firms. This evidence aligns with the findings in Xiong, Wang, Mayers, and Monga (2013), Seo (2014), and Sohn, Lim, and Ju (2014). 
However, inconsistent with Demirguc-Kunt and Huizinga (2010), no consistent influential factor was found in financing capability because no significance was found for the model 4 specification. However, the results showed that firm size was a pivotally influential factor in a negative direction to the profitability of Korean credit firms. Regardless of model specifications, all coefficients of firm size were negatively significant at the $1 \%$ level, which is inconsistent with the results in Lee, Lin, and Chen (2010).

Furthermore, all external factors regardless of model specifications were insignificant, which is inconsistent with the findings in Pasiouras and Kosmidou (2007) and Shin (2012). Thus, economic growth rate (Ec) and market rate (Mrate) showed insignificant coefficients.

Table 3: Test results for the influential factors in the profitability of credit card firms

\begin{tabular}{|c|c|c|c|c|c|c|c|c|}
\hline \multirow{2}{*}{$\begin{array}{c}\begin{array}{c}\text { Dependent } \\
\text { variable }=P t\end{array} \\
\text { Variables } \\
\end{array}$} & \multicolumn{2}{|c|}{ Model_Spec.1 } & \multicolumn{2}{|c|}{ Model_Spec.2 } & \multicolumn{2}{|c|}{ Model_Spec.3 } & \multicolumn{2}{|c|}{ Model_Spec.4 } \\
\hline & Coef. & t-stat. & Coef. & t-stat. & Coef. & t-stat. & Coef. & t-stat. \\
\hline Intercept & $0.0213^{* * *}$ & 5.19 & $0.0211 * * *$ & 5.01 & $0.0212 * * *$ & 4.45 & $0.0213 * * *$ & 4.52 \\
\hline Int $t_{t-1}$ & $0.0009^{* * *}$ & 3.14 & $0.0009 * * *$ & 3.11 & $0.0010 * * *$ & 3.23 & $0.0009 * * *$ & 3.21 \\
\hline$A f f_{t-1}$ & $-0.0016^{*}$ & -1.76 & $-0.0016^{*}$ & -1.75 & -0.0012 & -1.29 & -0.0012 & -1.20 \\
\hline$B d_{t-1}$ & $-0.1071 * * *$ & -4.96 & $-0.1072 * * *$ & -4.92 & $-0.1030 * * *$ & -4.70 & $-0.1042 * * *$ & -4.74 \\
\hline$F c_{t-1}$ & $0.0036^{* * *}$ & 4.09 & $0.0036^{* * *}$ & 4.04 & $0.0035 * * *$ & 3.97 & 0.0034 & 3.88 \\
\hline Asize $_{t-1}$ & $-0.0020 * * *$ & -5.10 & $-0.0012 * * *$ & -4.84 & $-0.0017 * * *$ & -4.53 & $-0.0012 * * *$ & -4.61 \\
\hline Intm $_{t-1}$ & & & -0.0089 & -0.19 & 0.0256 & 0.47 & 0.0284 & 0.52 \\
\hline$E c_{t}$ & & & & & -0.0631 & -1.06 & -0.0764 & -1.24 \\
\hline Mrate $_{t}$ & & & & & 0.0691 & 0.93 & 0.0570 & 0.75 \\
\hline Crisis_effect ${ }_{t}$ & \multicolumn{2}{|l|}{ No } & \multicolumn{2}{|l|}{ No } & \multicolumn{2}{|l|}{ No } & \multicolumn{2}{|l|}{ Yes } \\
\hline $\operatorname{Adj} . R^{2}$ & \multicolumn{2}{|c|}{0.4023} & \multicolumn{2}{|c|}{0.3912} & \multicolumn{2}{|c|}{0.3945} & \multicolumn{2}{|c|}{0.3921} \\
\hline$F$ & \multicolumn{2}{|c|}{$8.81 * * *$} & \multicolumn{2}{|c|}{$7.21 * * *$} & \multicolumn{2}{|c|}{$5.72 * * *$} & \multicolumn{2}{|c|}{$5.16 * * *$} \\
\hline D.W. & \multicolumn{2}{|c|}{1.6136} & \multicolumn{2}{|c|}{1.6163} & \multicolumn{2}{|c|}{1.6614} & \multicolumn{2}{|c|}{1.7174} \\
\hline
\end{tabular}

Notes: $*$ and $* * *$ denotes significant at $10 \%$ and $1 \%$ level respectively; hypothesis of $\mathrm{F}$ test is that all estimated coefficients are same; the value of the Durbin Watson test is between $0<\mathrm{D}$.W. $<4$, indicating no autocorrelation.

\section{CONCLUSION}

Based on a review of the relevant literature, this study conducted an empirical analysis of the relationship between profitability and the hypothetical factors by using recent Korean credit card business data. The results of this study could contribute to the research on the credit card industry. The results confirmed the statistical significance of factors that influence the profitability of Korean credit card firms, taking into account the effects of the global financial crisis. Most previous studies on the credit card industry tended to use data that were relatively out of date. However, the current study used recently compiled data to examine the influence of a particular factor that is at issue in Korea, which is the contribution of the credit card affiliate fee to operational revenue. 
The main findings are as follows. First, Korean credit card firms are positively susceptible to the portion of interest margin contribution in terms of business diversification, which is in line with Hyun (2014). It is understood that the profitability of Korean credit card firms is dependent on a high margin of borrowers with weak credit through card loans and cash advance services.

Second, the findings showed that risk management is an important contributory factor in increasing the profitability of Korean credit card firms, which supports Xiong, Wang, Mayers, and Monga (2013), Seo (2014), and Sohn, Lim, and Ju (2014). This result implies that predictions of default rates by borrowers is pivotal in reducing the costs of bad debt in credit card firms with the most detailed customer information compared with other financial institutions.

Third, large assets do not enhance the profitability of Korean credit card firms, which is inconsistent the findings in Lee, Lin, and Chen (2010). Firms with small assets require effective investment to increase their operating profits.

\section{REFERENCES}

Akin, G. G., Aysan, A. F., Kara, G. I., \& Yildiran, L. (2011). Nonprice competition in the Turkish credit card market. Contemporary Economic Policy, 29(4), 593-604.

Bellotti, T., \& Crook, J. (2013). Forecasting and stress testing credit card default using dynamic models. International Journal of Forecasting, 29(4), 563-574.

Blejer, M., Feldman, E., \& Feltenstein, A. (2002). Exogenous shocks, contagion, and bank soundness: A macroeconomic framework. Journal of International Money and Finance, 21(1), 33-52.

Carter, D., \& McNulty, J. (2005). Deregulation, technological change, and the business-lending performance of large and small banks. Journal of Banking and Finance, 29(5), 1113-1130.

Demirguc-Kunt, A., \& Huizinga, H. (2010). Bank activity and funding strategies: the impact on risk and returns. Journal of Financial Economics, 98(3), 626-650.

Demirguc-Kunt, A., Laevan, L., \& Lebine, R. (2003). Regulations, market structure, institutions, and the cost of financial intermediation. National Bureau of Economic Research Working Paper No.9890.

Hyun, Y.-J. (2014). Policies to increase profitability of the credit card industry in Korea. Journal of Industrial Innovation, 30, 37-68.

Islam, S., \& Ahmed, M. D. (2012). Business process improvement of credit card department: Case study of a multinational bank. Business Process Management, 18(2), 284-303. 
Kassim, S., \& Manap, T. (2008). Consumer Credit and Monetary Policy in Malaysia. International Journal of Consumer Studies, 32(3), 188-193.

Lee, C.-C., Lin, T., \& Chen, C.-J. (2010). The determinant of customer profitability on the financial institution. The Service Industries Journal, 30(14), 2311-2328.

Pasiouras, F., \& Kosmidou, K. (2007). Factors influencing the profitability of domestic and foreign commercial banks in the European Union. Research in International Business and Finance, 21(2), 222-237.

Quayes, S., \& Hasan, T. (2014). Financial disclosure and performance of microfinance institutions. Journal of Accounting and Organizational Change, 10(3), 314-337.

Seo, J.-Y. (2014). A study on the determinants of business stability in credit card firms: Evidence from Korea. Asian Academy of Management Journal, 19(2), 105-122.

Shin, J.-H. (2012). A Study on the profitability of mutual savings banks. The Journal of Market Economy, 41, 75-98.

Sohn, S., Lim K., \& Ju, Y. (2014). Optimization strategy of credit line management for credit card business. Computers and Operations Research, 48, 81-88.

Stever, R. (2007). Bank size, credit and the sources of bank market risk. Bank for International Settlements Working Papers No 238.

Tan, Y., \& Floros, C. (2014). Profitability and competition: Evidence from the Chinese banking industry. The Journal of Developing Areas, 48(3), 303-319.

Xiong, T., Wang, S., Mayers, A., \& Monga, E. (2013). Personal bankruptcy prediction by mining credit card data. Expert Systems with Applications, 40(2), 665-676. 